\title{
Língua, literatura e impressos franceses no Brasil do século XIX
}

\author{
Rita Cristina Lima Lages*
}

\section{Resumo}

A proposta deste trabalho é tratar da circulação de livros, e impressos de modo geral, que circularam no Brasil no século XIX, e que foram apropriados para o ensino da língua francesa. Nos primeiros momentos de escolarização do idioma, mapas que traziam os programas dos exames indicaram a utilização não só de manuais específicos, as gramáticas, como também a apropriação de obras de belas letras, de filosofia, política e economia para o ensino da língua. Tomaremos de modo mais específico a experiência da província de Minas Gerais. Destacou-se na província mineira uma ambiência cultural marcada por uma forte influência francesa que se fazia, sobretudo, pela circulação de livros e impressos.

Palavras-chave: Língua Francesa. História do Ensino. Impressos. Seculo XIX.

* Universidade Federal de Ouro Preto (UFOP). Professora adjunta do Departamento de Letras. Doutora e mestre em Educação pela Universidade Federal de Minas Gerais. Graduação em Letras e Pedagogia. Registro Orcid: https://orcid.org/0000-00030796-3363. 


\title{
Language, literature and french printed materials of the XIX century
}

\begin{abstract}
This study aims at analyzing the circulation of books and other printed materials which were in circulation in Brazil in the XIX century and were later used for teaching the French language. Early in to the institutionalization of French language teaching, guidelines featuring examination programs revealed that not manuals such as gram books as well as fine art pieces, philosophical, political and economics materials were being used as teaching resources. The Brazilian province of Minas Gerais experienced a remarkable cultural environment marked by the French influence exerted through the circulation of books and other printed materials.
\end{abstract}

Keywords: French Language. History of Teaching. Publications. XIX Century.

Recebido em: 24/03/2020

Aceito em: 08/06/2020 
A proposta de artigo é tratar dos usos e circulação de livros e demais impressos franceses no Brasil nas primeiras décadas do século XIX, tomando, de modo mais específico, a experiência da província de Minas Gerais. Interessa-nos identificar e analisar os impressos - e suas temáticas - em circulação e como estes foram apropriados para os usos escolares. A predominância de títulos diversificados, publicados em língua francesa compondo acervos de bibliotecas públicas ou particulares, lotes comprados em leilões ou mostrando-se em anúncios de jornais, evidenciava a França como grande produtora e comerciante do conhecimento. Essa comercialização, desencadeada pelo envolvimento direto dos empreendedores da imprensa no processo de difusão de todos os tipos de saberes levou o pesquisador Peter Burke (2003, p. 145) a utilizar a expressão "o negócio do iluminismo". Temos, pois, que esse "grande negócio" se fez notar no Brasil, elevando, consequentemente, a língua francesa como veículo, como mediadora de acesso aos conhecimentos produzidos.

\section{Língua e cultura francesa no Brasil, no século XIX}

Ao discutir sobre as relações e as implicações dos intelectuais na sociedade e na política, no âmbito Brasil-França, Wilma Peres Costa (2003) fala das rotas de peregrinações que se deram, sobretudo, no final do século XVIII e de viagens de intelectuais no século XIX, e expõe diferentes características para os dois movimentos. A peregrinação "explorava a afinidade existente entre o processo de formação dos intelectuais como categoria social e como carreira, e o de formação do sentimento nacional." (COSTA, 2003, p. 58, grifos da autora). Já a viagem, 
passa a ser entendida não apenas como estratégia de autoconhecimento, mas também de conhecimento objetivo e científico do mundo, a partir das duas grandes correntes que alimentam de forma combinada e contraditória o século XIX, o Romantismo e o espírito científico" (COSTA, 2003, p. 62, grifos da autora).

De acordo com a autora,

a partir das primeiras décadas do século XIX, a atração pela América do Sul foi muito intensa nos roteiros dos viajantes. Esse movimento associa-se em primeiro lugar à atração que exercia sobre cientistas e geógrafos, um continente que ficara fechado à exploração de estrangeiros durante todo o período colonial (COSTA, 2003, p. 64).

É importante destacar, no caso do Brasil, a abertura dos portos às nações estrangeiras em 1808, para melhor entender a intensificação das relações Brasil/França nos mais diversos domínios a partir de então. Ainda segundo Costa (2003):

Com o fim das Guerras Napoleônicas, a motivação científica francesa ganha corpo e a ela não era estranha essa motivação econômica e geopolítica. Com as guerras coloniais do fim do século XVIII e a venda da Louisiana em 1812, os franceses haviam sido praticamente expulsos da América do Norte, enquanto, com os movimentos de Independência, assistiam crescer a influência econômica e política da Inglaterra no continente. $\mathrm{O}$ contexto da rivalidade anglo-francesa é, assim, o mais relevante para entender a dinâmica da aproximação entre França e América do Sul, dinâmica esta que procurou compensar a menor presença econômica com a busca de uma hegemonia no campo cultural. (COSTA, 2003, p. 64).

Em um estudo sobre as práticas de leitura, de instrução e de línguas no Brasil colonial, Luiz Carlos Villalta (1997) refere-se à presença francesa nesses domínios: a partir do final do século 
XVIII, o francês passa a concorrer com o latim como língua culta, seguido de longe pelo inglês. Ele cita os relatos do viajante Saint-Hilaire, que diz ter conhecido homens instruídos que liam autores franceses e que haviam aprendido francês sem terem sido instruídos por mestres e, além disso, que o praticavam muito entre si. Conforme Villalta, as obras publicadas nesse idioma passam a compor o catálogo de bibliotecas coloniais, a língua viria influenciar no léxico, como, por exemplo, naquele dos inconfidentes de 1794, que vão utilizá-la em seus discursos. Vista então como portadora de ideias revolucionárias, essa língua era considerada como perigosa para os habitantes da colônia. Sendo assim, muitas famílias proibiam seus filhos de a praticarem.

Estudos como esses de Villalta, quer tratem da história da leitura, quer dos impressos de modo geral, no Brasil, são grandes portadores de elementos sobre as mais diversas formas da circulação da língua francesa no Brasil.

Trazem esses elementos de forma expressiva, as pesquisas realizadas por Nelson Schapochnik (1999) sobre as práticas de leitura na Biblioteca Pública da Corte Imperial — ou Biblioteca Nacional do Rio de Janeiro. Para investigar algumas dessas práticas, tomou como fonte o livro de consultas públicas, no qual constava o registro, realizado pelos amanuenses, das obras retiradas. O livro, localizado na Seção de Manuscritos, trazia o título das obras solicitadas diariamente no período de 1843 a 1856.

Com base nesse fundo, Schapochnik (1999, p. 300-301) compõe um quadro no qual pretende indicar o movimento dos consulentes na Biblioteca, além de realizar uma tabela na qual procura "avaliar as habilidades linguísticas dos leitores 
que frequentaram a instituição". Ainda que seja questionável a expressão habilidades linguísticas, dada a necessidade de uma pesquisa mais profunda das formas de apropriação da parte daqueles leitores que retiram obras estrangeiras, a tabela1 abaixo fornece excelentes informações sobre a circulação de obras francesas no Brasil do século XIX, além de indiciar uma grande difusão da prática da leitura em língua francesa.

\section{TABELA 1}

Consulta pública (1843-1856) - Consultas por língua

\begin{tabular}{lll}
\multicolumn{1}{c|}{ LÍNGUA } & \multicolumn{1}{c|}{ TOTAL } & \\
\hline PORTUGUÊS & 12577 & 65,45 \\
FRANCÊS & 5576 & 29,01 \\
LATIM & 511 & 2,65 \\
OUTRAS & 206 & 1,05 \\
INGLEES & 173 & 0,90 \\
ESPANHOL & 172 & 0,89
\end{tabular}

Nota: * Inclui: Sem identificação (141 -0,73\%); italiano (40-0,2\%); alemão (2-0,1\%); grego $(4-0,02)$.

Fonte: SHAPOCHNIK, 1999, p. 301.

Com base nos dados apresentados, Schapochnik comenta:

A tabela [1] não deixa dúvidas sobre a suplantação do latim pela língua francesa. ${ }^{1} \mathrm{E}$, em alguns casos, o domínio do francês ameaça ou mesmo supera o emprego do vernáculo, indicando simultaneamente as deficiências do mercado editorial luso-brasileiro e um misto de fascínio e necessidade que esta língua exercia nos diversos níveis de ensino (SHAPOCHNIK, 1999, p. 301).

1 Observação também feita nos estudos de Villalta (1997), quando fala a respeito de o francês vir concorrer com o latim como língua culta já no final do século XVIII. 
$\mathrm{O}$ autor ainda apresenta um diagnóstico identificado com base em um artigo de Gama (1844 apud SHAPOCHNIK, 1999, p. 302), transcrito na coluna "Variedades" do Jornal do Commercio do Rio de Janeiro, não só do ensino da língua portuguesa, considerado deficiente, como também do ensino de línguas, definido como precário:

O que nos falta é haver quem faça instruhir, antes de tudo, a nossa mocidade em sua língua nacional. Qual é ordinariamente a nossa educação a este respeito? O menino apenas lê na escola quatro regrinhas, a que dão o nome de grammatica portugueza, e sem mais nenhum conhecimento da língua materna, do que o usual e do gosto commum miseravelmente amalgamado com inúmeros barbarismos, solecismos e gallicismos, passa logo a estudar mui superficialmente o latim, e dali o francez e mais francez. O jovem lê por outros livros: e o resultado de tudo isso é ficar fallando uma geringonça ridícula, que nem é francez nem portuguez. [...]

As escolas e mestres de francês e inglês andão por ahi a granel: só ninguém cuida de aprender a língua materna: porque? Talvez por entenderem que não é preciso aprender, que basta o portuguez que nos ensinarão nossas amas, nossos escravos, nossos mestres capadócios (muitos dos quais escrevem saptisfeito e progunta), e o sarapatel gallo-luso que geralmente se falla por ahi; mas se não sabemos a precito de nossa própria lingua, como aprender capazmente as estranhas? (GAMA, 1844 apud SHAPOCHNIK, 1999, p. 302.).

Por sua vez, ao buscar descrever e analisar as ideias políticas e filosóficas que estariam presentes e atuantes em Minas Gerais, no século XIX, José Carlos Rodrigues (1986) fala a respeito das principais cidades mineiras onde essas ideias circulavam, como também da existência de bibliotecas e livrarias que aí se configuravam como peça fundamental. As cidades de Vila Rica (hoje, Ouro Preto), Mariana, Sabará, São João Del Rei, São 
José Del Rei (hoje, Tiradentes) e algumas outras cidades iriam comungar as mesmas ideias da Ilustração e dos enciclopedistas. Evidenciar-se-iam como os principais centros de circulação dessas ideias a biblioteca de São João Del Rei e a famosa Livraria Cônego Luís Vieira (em Ouro Preto), ${ }^{2}$ nas quais se encontravam presentes as principais obras dos ideólogos e enciclopedistas franceses.

Rodrigues (1986) considera o cônego Luís Vieira um representante típico que viria motivar todo o movimento da Inconfidência. Encontra-se registrada nos Autos da Devassa da Inconfidência Mineira uma extensa lista de livros confiscados da biblioteca do cônego, a maioria deles, de autores franceses, dentre os quais: Condillac, Diderot, Voltaire, D'Alembert, de Fleury, de Bossuet, de Tissot, de Fabri, etc.. Cabe ressaltar que existiam, até mesmo, obras de autores de outras línguas traduzidas e publicadas em língua francesa, como é o caso do tratado do escocês Cullen, cuja obra adotada era Eléments de médecine pratique. Algumas outras obras eram publicadas em latim e os títulos em língua portuguesa constituíam a minoria (RODRIGUES, 1986).

Também tomando para seus estudos os usos, a circulação e a apropriação de livros e impressos de forma geral, na Província de Minas Gerais, Christianni Cardoso Morais (2001) apresenta um trabalho sobre as estratégias de difusão da cultura escrita na Vila de São João Del Rei, entre 1824-1831, estratégias analisadas, principalmente, por intermédio da criação e do funcionamento da Livraria Pública de São João Del Rei ou da Biblioteca Baptista Caetano d'Almeida. ${ }^{3}$ Ao colocar como título

\footnotetext{
2 Cf. RODRIGUES, 1986, p. 25. O cônego Luis Vieira era também professor de Filosofia do Seminário de Mariana.

3 A livraria pública de São João Del Rei, inaugurada em 1827, é apontada pela autora como a primeira Biblioteca Pública da Província de Minas Geraes. (Cf. MORAIS, 2001, p. 61)
} 
de um capítulo da dissertação "Luzes para a Vila de São João Del Rei: o projeto de criação da Livraria Pública", a autora torna expresso a função que teria desempenhado a livraria. Sobre os sentidos do projeto de criação da biblioteca, a autora comenta:

\begin{abstract}
À primeira vista, a criação de uma Biblioteca Pública na Vila de São João del Rei pode parecer uma excentricidade, mas esse projeto só tem sentido quando inserido em seu contexto, num espaço urbano intensamente ativo e projetado por uma parcela da elite local que se referenciava nos ideais iluministas. De acordo com esse ideário, a prática da leitura — a leitura útil - se constituía como uma das estratégias através das quais era possível 'civilizar' os indivíduos, tornando-os cidadãos submetidos à ordem pública e ainda levar a recém-fundada nação brasileira a ingressar na corrida constante que culminaria com o 'progresso'. Tendo em vista a necessidade de se constituírem um povo e uma nação civilizados, as elites brasileiras buscavam inspiração na França, tornando esse país o modelo de civilização almejado. Daí o interesse pelos espaços de sociabilidade, pelo idioma, livros e autores franceses. (MORAIS, 2001, p. 172, grifo da autora).
\end{abstract}

Um estudo realizado por Marco Morel (2005) pode ser tomado como importante referencial que ajudaria a situar e compreender melhor essas práticas culturais que permitiram, por meio, sobretudo dos impressos - nas suas mais variadas formas de produções - , possibilidades de circulação e usos da língua francesa no Brasil, no século XIX. As análises de Morel incidem sobre as transformações dos espaços públicos - mais exatamente do Rio de Janeiro, entre 1820 e 1860 — promovidas por complexas redes de sociabilidades, da qual fizeram parte a imprensa e os agentes políticos. Ocupa lugar central nessa rede, o editor e livreiro francês Pierre Plancher, que se estabeleceu no Rio de Janeiro. Os livros e os demais impressos franceses 
- considerados como uma herança da Revolução francesa vendidos em sua livraria na rua do Ouvidor, teriam funcionado como os mediadores das ideias das luzes, ao criar "uma teia entre as práticas culturais de edição e venda, a organização da cultura no Estado nacional que se construía e as ideias políticas que balizavam e criavam referências."(MOREL, 2005, p. 59).

Essa hegemonia da referência francesa no campo cultural brasileiro foi bastante explorada por um estudo - que precede a todos os citados — de Gilberto Freyre (1940), no qual ele toma, como ele próprio diz, "por ponto de apoio" a figura e o percurso de um engenheiro e arquiteto francês no Brasil, Louis Léger Vauthier, estabelecido em Pernambuco, entre 1840 e 1846. Ao orientar suas análises pela intensificação da influência da França, nas primeiras décadas do século XIX, Freyre traça, primeiramente, um breve panorama sobre as relações estabelecidas entre Brasil e França desde a Colônia. Em seguida, trata da presença francesa que se deu, segundo seus estudos, não só no campo das ideias mediadas pelos livros, mas também pela forte presença de franceses no Brasil, nas primeiras décadas do XIX, que, por sua vez, proporcionariam uma influência da cultura e da técnica francesas. Segundo Freyre (1940),

com a vinda para o Brasil, depois da Chegada de Dom João VI, de artistas, engenheiros, mestres, parteiras, commerciantes, cozinheiros, pasteleiros, modistas, retratistas, propagandistas de drogas, representantes de indústrias, e também de emigrados políticos ilustres, alguns até fidalgos, se afirmou entre nós, de modo mais vigoroso, a influência da cultura e da technica francesas. É certo que o livro francês, ou melhor, a língua francesa, pelo seu puro prestígio de lingua literária e diplomatica - ainda que de hereges - agiu grandemente a favor da irradiação da cultura francesa no Brasil: isto é, entre grupos de elite. (FREYRE, 1940, p. 34) 
Propondo-se apresentar uma influência que teria se exercido pelos agentes "technicos", conforme Freyre os denomina, o autor toma como fonte aproximadamente dois mil anúncios de jornais ${ }^{4}$ do Rio de Janeiro, Bahia e Pernambuco, por meio dos quais esses agentes se permitiram ver. Indivíduos, que os classifica como

quase sumidos ao lado do que a sciencia, a pedagogia, a literatura e arte francesas enviaram até nós de mais grandioso - a missão artística de 1816, por exemplo, com o seu Grandjean de Montigny e o seu Taunay é que os anúncios de jornaes apresentam uma massa enorme de factos typicos, um material cheio de repetições valiosas para effeitos de explicação scientifica, de esclarecimento psychologico, de comparação históricosocial; e não apenas de fixação e interpretação do facto rigorosamente - ou convencionalmente histórico: interpretação circunscripta ao único ou ao extraordinário. (FREYRE, 1940, p. 35).

Além dos anúncios dos "serviços" oferecidos ao público por esses indivíduos franceses, Freyre (1940, p. 84-85) também trata daqueles da venda de livros de mesma origem, pois afirma que "não é só o livro francês de literatura, de philosophia, de política, que apparece com frequência naqueles annuncios: também o livro technico, original ou traduzido."

E, por meio do percurso do engenheiro Vauthier, em Pernambuco, caso exemplar da influência descrita por Freyre, o autor conclui:

Em Vauthier e no grupo de technicos franceses, seus colaboradoes e auxiliares, encontra-se um foco activissimo do que os modernos estudiosos ingleses e norte-americanos de culturologia chamariam de "culture-spreed", ou de propagação de cultura, por meio

4 Freyre (1940, p. 35) classifica esses anúncios como material "virgem" para a pesquisa. 
da technica acompanhada de irradiação: a) comercial, de productos; b) intelectual, de idéias; c) principalmente social, de costumes, usos e estilos de vida. (FREYRE, 1940, p. 36)

Essa presença francesa em vários aspectos da vida social brasileira da qual fala Freyre será posteriormente tratada por Luiz Felipe de Alencastro (2004, p. 39), em seus estudos, a respeito da referência europeia no Brasil Imperial: "Com a inauguração, a partir de 1850 , de uma linha regular de navio a vapor entre Liverpool, na Inglaterra e o Rio de Janeiro, o tempo imperial entra em sincronia com o tempo da modernidade europeia." Segundo esse autor, a partir de 1852, confirma-se o francesismo das elites brasileiras, que estabelece, além de modas, modos de vida:

Folhetins, operetas, e romances vindos da França difundiam no Império a imagem de um modo de vida rural, conservador e equilibrado, entrelaçado de aldeias e pequenas cidades nas quais o padre e o militar, quando havia casernas, apareciam como personagens de prestígio.

Desenhava-se a representação de uma sociedade rural francesa que aparecia como um paradigma da civilidade para a sociedade tropical e escravagista dos campos do Império. (ALENCASTRO, 2004, p. 42).

Lopes (1990), a respeito da educação feminina em Minas Gerais no século XIX, mostra a presença francesa nesse domínio:

É ainda Paris ditando a moda e o bom-tom das boas famílias burguesas, interiorizando costumes, hábitos, passando cordões de isolamento por toda a sociedade, desinfetando os espaços públicos, editando e exportando manuais de delicadeza, de guloseimas, de qualidade e de defeitos das meninas e mocinhas casadoiras [...]. (LOPES, 1990, p. 34.). 
Diva do Couto Gontijo Muniz (2003), também ao se dedicar à investigação sobre educação das moças mineiras nesse período, fornece elementos a respeito dos colégios femininos da província. Ela nos fala sobre as irmãs francesas da ordem de São Vicente de Paula, trazidas da França em 1849 pelo, então, Bispo de Mariana, D. Antônio Ferreira Viçoso, especialmente para educar as moças mineiras:

Civilizar as mineiras - e também alguns jovens
de outras províncias - foi tarefa e desafio a que as
vicentinas dos colégios Providência e N.S. das Dores
não se furtaram e, mesmo, neles se empenharam com
vigor desdobrado. Elas assim procederam não apenas
pelas pressões familiares e pelo propósito de que se
achavam imbuídas de transformar suas alunas em 'boas
cristãs' e 'boas mães' mas, também, pela meta buscada
de fazer com que as 'preguiçosas', 'geniosas' e 'rudes'
mineiras adotassem comportamentos 'civilizados', ou
seja, segundo o padrão cultural francês.(MUNIZ, 2003,
p. 238. )

Segundo Muniz, a língua francesa foi nesse momento um ingrediente de formação escolar cuja intenção era homogeneizar condutas, além de conferir uma distinção social e um estatuto de educadas àquelas jovens mineiras.

\section{O ensino da língua francesa: língua, literatura e filosofia nas práticas escolares}

Após tratar da circulação da cultura e da língua francesa em Minas Gerais e no Brasil no século XIX, apresentamos a seguir os primeiros momentos de formalização do ensino escolar desse idioma, destacando manuais, métodos e autores mobilizados para o ensino. 
Por meio de uma busca de grande fôlego, encontrei alguns documentos produzidos por professores e alunos que, se não me permitiram uma ideia exata, forneceram-me grandes indícios sobre o ensino/aprendizagem da língua. Localizei no fundo da Instrução Pública e no da Presidência da Província do Arquivo Público Mineiro (APM) correspondências entre professores e o governo, descrevendo as práticas realizadas na sala de aula, como também alguns mapas de alunos da aula pública de francês de Mariana, elaborados pelo professor na ocasião da realização de exames, entre 1836 e $1838 . .^{5}$

Os dados trazidos por tais documentos propiciam análises em vários direcionamentos, mas o objetivo é ir ao encontro das seguintes percepções descritas a seguir. Em primeiro lugar, que conteúdos merecem ser selecionados pela escola e em que medida eles se articulam com os usos não escolares? Em segundo, serão tratadas as finalidades percebidas por meio dos conteúdos dos textos selecionados: que sensibilidades essas leituras possibilitariam desenvolver nos alunos? E, em terceiro, como a escola se apropria desse saber, ou seja, qual tratamento lhe é conferido na composição das práticas de ensino, e como esse saber praticado no cotidiano escolar dialoga com as finalidades inscritas nas concepções do ensino?

Sobre a seleção dos conteúdos, os mapas de exames permitem uma aproximação do funcionamento escolar, pois, como afirma Chervel (1990, p. 206), os exames constituem um importante ponto na arquitetura das disciplinas, uma vez que as necessidades de avaliação dos alunos são produtoras de dois fenômenos que pesam no desenvolvimento das disciplinas ensinadas: o primeiro seria "a especialização de certos exercícios

5 Faz-se necessário relembrar aqui que até 1837 constava na província mineira apenas uma aula pública de língua francesa, funcionando em Mariana. 
na sua função de exercícios de controle"; o segundo, o "peso considerável que as provas do exame final exercem por vezes sobre o desenrolar da classe e, portanto, sobre o desenvolvimento da disciplina, ao menos em algumas de suas formas".

A respeito dos exames realizados na aula de Mariana, entre 1836 e 1838, o professor elaborou mapas (MINAS GERAIS, IP 3/2, cx 1 - pacotilhas 44 e 54; MINAS GERAIS, PP 1/42, cx 12 - pacotilha 70) com as seguintes informações: nomes dos alunos; data de matrícula; observações ou matérias dos exames, onde são listadas as "aptidões" desenvolvidas; obras escolhidas; além do envio de alguns exames realizados. No tratamento dos conteúdos serão consideradas, primeiramente, as obras que se encontram indicadas do seguinte modo:

1) Autores clássicos escolhidos pelo professor para servir de exame:

Jouy, Perrard, Droz, Hammonière, L'Homond, Perrard Eschola Laromiguière. (1836)

2) Autores clássicos para a leitura e tradução:

Laromiguière e Perrard (Liçõens de Philosophia), Jouy, Télémaque (Aplicação á moral e Política).

3) Autores clássicos da Gramática:

G. Hammonière, L'Homond. (1838)

Percebemos, portanto, nos primeiros momentos de escolarização da língua, a utilização não só de manuais específicos - no caso, as gramáticas - para o ensino, como também de outras áreas do conhecimento, como as de filosofia e belas letras, para se ensinar o francês. A partir dessas informações, tornase possível articular as práticas escolares aos outros usos do 
francês. Nesse sentido, as orientações de Pierre Arnaud (1989, p. 31) auxiliam para a melhor compreensão do processo de inserção de uma disciplina nos programas escolares, quando traz para isso a problemática da integração, que além de se constituir das finalidadesque the deve conferir o legislador, também se desdobra na representatividade cultural, ou seja, as práticas escolares de um saber serão representativas daquelas culturais, uma vez que se pode estabelecer uma relação de identidade ou de proximidade entre essas duas práticas, atentando para a percepção da transformação de uma prática em outra.

Voltando ao primeiro tópico deste artigo, percebe-se que a maioria dos autores mobilizados para o uso escolar estava presente nas mais diversas práticas culturais da língua francesa na província mineira nas primeiras décadas do século XIX. Para falar um pouco deles, encontraremos: as obras de Joseph Droz no catálogo da Biblioteca de Ouro Preto, em traduções publicadas em vários números do Jornal O Universal de Ouro Preto, citações de trechos em epígrafes desse jornal, e em anúncios de venda de livros do Astro de Minas de São João del-Rei; as de Perrard e Laromiguière aparecem também na composição da Biblioteca de Ouro Preto e em anúncios de venda de livros do Universal, o que nos leva a concluir que, retomando as proposições de Arnaud (1989) nos momentos iniciais da escolarização da língua, as práticas escolares mostraram-se representativas daquelas culturais.

Partindo do princípio de que a seleção de conhecimentos implica a seleção, também, de valores, como nos orientam Petitat (1994) e Hebrard (1990 e 1999), quais sensibilidades os conteúdos das obras de Jouy, Perrard, Droz, Laromiguière, Fénelon possibilitariam desenvolver nos alunos? 
As Aventuras de Telêmaco, de Fénelon, é uma obra classificada por alguns estudos do livro e da leitura como aquela das "belas letras". Villalta (2000), ao tomar os inventários para analisar a posse de livros no Brasil colonial, classifica as obras como ciências sacras ou profanas. Nessas últimas, considerando, sobretudo, a circulação nos séculos XVII e XVIII, enquadravamse os livros de belas letras, história profana, dicionários, ciências, direito-filosofia, filosofia, geografia, entre outras). Em suas pesquisas, Villalta afirma que Fénelon, ao qual ele confere a rubrica de beletrista, com sua obra As Aventuras de Telêmaco, encontra-se como um das mais frequentes nos inventários estudados. (Villalta (2000), p. 183-212)

Esse dado trazido pelos estudos acima vem, por sua vez, permitir a articulação da escola com seu entorno, levando em conta, para isso, a apropriação de uma obra de grande circulação cultural, no caso Télémaque, para as práticas escolares. Além da identificação do uso dessa obra para os exames de alunos, também foram os trechos dela selecionados para os exames de tradução e versão em concursos dos professores públicos de língua francesa.

Do que trata exatamente tal obra de Fénelon (1651-1715)? ${ }^{6}$ Esse autor do século XVII era preceptor de um aluno da realeza francesa e tornou-se escritor de fábulas para serem utilizadas nos seus princípios educativos. Em 1699, publicou Télémaque, um romance que, ao narrar as viagens e aventuras de Telêmaco, filho de Ulisses e Penélope, pode ser definido como mitológico, mas com objetivos didático-pedagógicos, uma vez que apresenta tratados de moral e princípios que deveriam ser adquiridos pelo viés do ensino de literatura. Ou seja, uma literatura com propósitos instrumentais.

$\overline{\mathrm{O}}$ acesso a algumas obras mobilizadas para ensino da língua francesa, como Télémaque, cujo conteúdo será agora tratado, tornou-se possível pela disponibilização das mesmas pela Biblioteca Nacional Francesa, no seguinte endereço: gallica.bnf.fr. 
Em relação aos outros autores, Jouy, Perrard, Droz, Laromiguière, não foi encontrado acúmulo de pesquisas que tratasse de suas obras. Mas uma breve abordagem desses autores se tornou possível pelos estudos de Rodrigues (1986), que faz algumas considerações a respeito da corrente filosófica de Laromiguière; por meio do site da Biblioteca Nacional Francesa, ${ }^{7}$ que disponibiliza as obras de Laromiguière, Droz e Jouy; e pelo contato direto com uma das publicações de Perrard (1834).

A propósito de Laromiguière (1756-1837), cuja obra traz o título de Leçons de Philosophie ou Essai sur les facultés de l'âme, Rodrigues (1986)), faz algumas referências, classificando-o como um dos "precursores do espiritualismo eclético de Victor Cousin, Maine de Biran e outros ecléticos franceses". Sobre Laromiguière e sua corrente filosófica na França, Rodrigues (1986) ainda considera:

Laromiguière conserva ainda algo de Condillac, mas combinado prudentemente como o espiritualismo em voga. A filosofia dos liceus, sob a Restauração, tenta demonstrar a existência de Deus, a espiritualidade e o livre-arbítrio. A Metafísica é a continuação da política. Reafirmando a realidade do espírito e da consciência como constitutivas para a solução do problema da origem das ideias, os ecléticos buscariam sobretudo uma coerência com o sistema. (RODRIGUES, 1986, p. 118.)

Perrard (1795- ?) pode se classificado como pertencente à escola de Laromiguière, ao publicar, em 1834, Manuel de Logique e de Philosophie e Une Logique Classique d'après les Príncipes de Laromiguière. Ao ser indicado nos exames de alunos de francês da província mineira na década de 1830 , é apresentado da seguinte maneira: Perrard, Escolla de Laromiguière.

7 Cf. gallica.bnf.fr: 
Droz (1773-1851), autor bastante citado nos periódicos mineiros na primeira metade do século XIX, teve um trecho de sua obra Aplicação da Moral à Política citado como epígrafe do jornal $\mathrm{O}$ Universal, de Ouro Preto, durante alguns anos: "A ordem é banida dos lugares onde habita a tirania: a Liberdade se desterra dos paizes onde a desordem reina; estes dous bens deixão de existir, quando os separão". ${ }^{8}$ Além dessa obra, outra que aparece em traduções nos periódicos da província mineira é Économie politique, ou Principes de la science des richesses, na qual ele vai tratar dos objetivos da economia política, da importância da distribuição das riquezas e propriedades, das divisões das propriedades territoriais, da liberdade da indústria, leis que regulam as qualidades que devem ter os produtos, etc.

Jouy (1764-1846), publicou État actuel de l'industrie française, ou Coup d'oeil sur l'exposition de ses produits, dans les salles du Louvre, en 1819, livro que apresenta uma descrição minuciosa sobre o progresso da indústria francesa constatado pela exposição de 1819 .

Essa breve apresentação dos autores selecionados permite pensar na diversidade de conteúdos mobilizados para o ensino da língua. Ao lado das aventuras do personagem Telêmaco, obra das belas letras do século XVII, imbuída de princípios didáticopedagógicos que possibilitariam desenvolver nos alunos a sensibilidade para uma educação estética, moral e cívica, baseada na imitação dos modelos gregos, encontram-se outros textos, do século XIX, cujos conteúdos tratam de temas contemporâneos da época, como economia, indústria, política, filosofia, etc. Pensar na apropriação de tais conteúdos pelos alunos, conforme nos sugere Hébrard (1999, p. 77) - naquilo que fazem com esse

\footnotetext{
8 Droz publicou os seguintes trabalhos: I. Essai sur l'art d'être heureux. Éloge de Montaigne. Études sur le beau dans les arts; II. De la philosophie morale. Applications de la morale à la politique. Notice sur Michel de L'Hospital. Discours de réception à l'Académie française; III. Économie politique, ou Principes de la science des richesses. (Cf. gallica.bnf.fr)
} 
"equipamento mental", do qual a escola lhes dotou, no momento em que se encontram nas redes de sociabilidade nas quais estão implicados - é romper com a ideia de pura instrumentalidade da qual é incorporado o ensino do francês ao ser inserido nos "cursos preparatórios" da província mineira nas primeiras décadas do século XIX.

Mas, ao serem trazidas para a escola, de que forma essas obras de belas letras, filosofia, economia e política são apropriadas para ensinar francês? Embora listadas nos mapas como aquelas que serviriam para a tradução e leitura, os exames realizados pelos alunos mostram que, na realidade, também são extraídos trechos para servir às "análises gramaticais". A transcrição de um exame (MINAS GERAIS, PP 1/42, cx 12 - pacotilha 70) possibilita ver como isso se operava: ${ }^{9}$

Perrard, T. 1er. p. [196?]

La morale tire son nom du mot grec, qui signifie moeurs

Analyse

La - article singulier feminine qui qualifie morale Morale - Substantif singulier feminine sujeto du verbe tire.

Tire - verbe actif à la trosième personne du singulier de

9 Aqui é proposta uma tradução "aproximada" do exame. Dadas as diferenças de estrutura entre as duas línguas, foi feita uma tradução mais literal para permitir uma compreensão da análise gramatical exigida:

A moral tira seu nome da palavra grega que significa costumes.

A - artigo singular feminino que qualifica moral.

Moral - substantivo singular feminino sujeito do verbo tirar.

Tira - verbo ativo na terceira pessoa do singular.

Seu - adjetivo possessivo singular masculino que determina "nom" (nome, substantivo).

Nome - substantivo singular masculino.

$\mathrm{Da}$ - artigo contraído por de a.

Palavra - substantivo singular feminino.

Grega - substantivo masculino singular.

Que - pronome relativo.

Significa - verbo ativo na terceira pessoa do singular do presente do indicativo.

Costumes - substantivo de dois gêneros plural. 
l'indicatif présent du verbe tirer.

Son - adjectif possessif singulier masculin qui determine nom.

Nom - substantif singulier masculin.

Du - article contracté pour de le.

Mot - substantif singulier masculin

Grec - substantif masculin singulier.

Qui - pronom rélatif.

Signifie - verbe actif à la troisième personne du singulier de l'indicatif présent.

Moeurs - substantif des deux genres Pluriel

Joaquim Pinto Monteiro.

(Feito em Aula Pública no dia 15 de dezembro de 1838). (MINAS GERAIS, PP 1/42, cx 12 - pacotilha 70.)

Com base em tais exercícios, torna-se possível vislumbrar de que forma os imperativos escolares atuam na escolarização dos saberes em circulação. Os conteúdos de filosofia, ao serem trazidos para as práticas de ensino da língua francesa, investemse de novos significados quando submetidos aos imperativos didáticos da escola que, nesse sentido, se apropria deles para se ensinar gramática. Onde encontrará o ensino da gramática o seu sentido senão na escola mesma? Esbarramos aqui, portanto, da dimensão da cultura escolar apresentada por Chervel (1998).

Os mapas traziam também o conteúdo gramatical a ser avaliado. E os exercícios acima demonstrados tratam exatamente dessa questão. Este foi o programa gramatical apresentado nos exames de 1836:

\section{Gramática}

Seu uso e propriedade. Sua divisão em nomes substantivos e adjetivos; seus gêneros, seus números, definição do artigo e dos pronomes em geral.

Do verbo, seus tempos, pessoas e numeros; formação de seus tempos, etc.

Do advérbio, preposição, conjunção, justaposição. 
Da syntaxe, dos adjetivos e dos verbos; concordância do verbo com o sujeito; lugar do sujeito no verbo, regimes directo ou indirecto dos verbos. (MINAS GERAIS, IP $3 / 2$, cx 1 - pacotilha 54)

Além da gramática, quais outras aptidões estavam previstas para os exames? Os três mapas encontrados nos permitem saber das habilidades previstas para os exames: tradução, versão, leitura, gramática, composição. Nesses documentos não encontrei menção à aptidão às vezes classificada como fala ou conversação. O que denota um distanciamento das concepções de ensino apresentadas, visto que esta estava prevista para ser praticada no ensino das línguas estrangeiras, conforme os programas oficiais. Entretanto, é preciso dizer que o desenvolvimento dessa habilidade não esteve ausente das práticas de ensino. O memorial do professor público de francês Elias Diogo e Costa, do Colégio Nossa Senhora d'Assumpção, de Ouro Preto, revela sua prática de ensino no ano de 1842. Vejam-se alguns trechos:

[...] era do seu imprescriptivel dever entrar nos exercicios do verdadeiro methodo que solidamente realizasse $a$ pratica total de todos os principios inscriptos[...] no circulo gramatical da lingua Franceza [...] pois que até então se havia limitado o ensino público á rotina de simples traducções.

Enquanto ao ensino da Língua Franceza o abaixo assignado não considerou somente como assumpto de seus trabalhos o idioma traduzido; mas dirigio tambem suas atenções á prática que transmite o idioma pela conversação familiar, bem como aquela que ensina a representa-lo por caracteres escriptos.

[...] Para o desempenho dos trabalhos gramathicais da Lingua Franceza, reclamou-se um Praticador 
cuja estampa graduada com sua escala de palmos e polegadas formou e apresentou o abaixo assignado, demonstrando a utilidade deste utensilio pela facilidade de patentear com hum só golpe de vista a toda huma classe atenta ainda mesmo a mais numerosa a pratica diaria da conjugação, versão, composição, ortographia, etymologia, frases peculiares do idioma. [...] Reclamarão-se os tres diccionarios de consulta para que permanentes na mesa da aula (utensilio que não existia) resolvessem nas traducções e composição as ocorrencias dificeis dos usos particulares e systema privativo da lingua; contudo não foi atendida esta urgente reclamação.

[...]. (MINAS GERAIS, PP 1/42, cx 13 - pacotilha 57, grifos nossos)

Os dados apresentados pelo professor Elias Diogo e Costa sobre sua prática cotidiana de ensino, se aproximam, por sua vez, das concepções de ensino operantes na época, uma vez que esse sujeito nos diz ensinar todos os "princípios" da língua francesa. No seu discurso, a conversação não estava ausente.

Assim como as análises empreendidas sobre os mapas de exames de alunos da primeira Aula Pública de francês da província mineira, encontramos no exercício do professor do Colégio Nossa Senhora d'Assumpção elementos que nos conduzem a classificá-lo como praticante de uma cultura escolar. Elementos definidos pelo professor como trabalhos gramaticais, conjugação, versão, ortografia, etymologia, frases peculiares do idioma, etc., reforçando a ideia de que, na cultura escolar, os sentidos dessas práticas vão se encerrar na escola.

Ao tomar os dados em seu conjunto, tanto aqueles relacionados às concepções de ensino de uma língua estrangeira como aqueles encontrados sobre a prática cotidiana escolar, mesmo considerando que estes últimos nos aproximam de forma indiciária do cotidiano da sala de aula, identifico a 
predominância de práticas de "tradução, gramática e leitura" no ensino da língua, mas que as outras aptidões ou princípios - o que hoje se denomina "competências" -, como conversação ou a escrita, não estiveram ausentes nem das concepções, tampouco das práticas ensino.

No entanto, o exercício da tradução se mostrou como a principal habilidade a ser desenvolvida no ensino da língua. Se os conhecimentos que circulavam por meio dos impressos encontravam-se produzidos em sua maioria em francês, logo, a língua se tornou mediadora; era ela, portanto, que podia promover o acesso a esses conhecimentos.

\section{Considerações finais}

Este artigo tratou da circulação da língua e da cultura francesa no Brasil, e em Minas Gerais, a partir das primeiras décadas do século XIX, quando o francês passa a concorrer com o latim como língua culta. Esse movimento se justificou pelo fato de se pretender encontrar elementos que nos levassem a compreender o processo de inserção da língua francesa na instrução pública, passando das práticas culturais para as práticas também escolares. Destaca-se aí, por meio do acúmulo de estudos - sobretudo aqueles da história do livro e da leitura - a forte presença da cultura francesa no Brasil, que se fazia notar especialmente pela circulação de livros e impressos.

Nos primeiros momentos de escolarização, mapas que traziam os programas dos exames, além dos exercícios realizados pelos alunos, indicaram a utilização não só de manuais específicos, as gramáticas, como também a apropriação de obras de belas letras, de filosofia, política e economia para o ensino da 
língua. Ao considerarmos o francês na arquitetura dos saberes, autores e livros selecionados, configurou-se a ideia de o ensino da língua ter-se inserido na permanência da cultura de ensino clássico-humanista - baseada na imitação dos textos gregos e latinos, com princípios de uma educação para a retórica, a eloquência, mas também para a moralidade e civilidade.

\section{Referências}

ALENCASTRO, Luiz Felipe de. Vida privada e ordem privada no império. In: ALENCASTRO, Luiz Felipe de . (org.). História da vida privada no Brasil: a corte e modernidade nacional. São Paulo: Cia. das Letras, 2004.

ARNAUD, Pierre. La mise em forme scolaire de l'educacion phisique. Revue Française de Pédagogie, p. 29-34, 1989.

BURKE, Peter. "Heu domine, adsuntturcae: esboço para uma história social do latim pós-medieval". In: BURKE, Peter; PORTER, Roy (org.). Linguagem, indivíduo e sociedade: uma história social da linguagem. São Paulo: UNESP, 1993.

BURKE, Peter. Uma história social do conhecimento: de Gutenberg a Diderot. Rio de Janeiro: Zahar, 2003.

CHERVEL, A. A história das disciplinas escolares: reflexões sobre um campo de pesquisa. Teoria e Educação, Porto Alegre, 1990 , v.2, p. $177-229$..

CHERVEL, André. La culture scolaire: une approche historique. Paris: Belin, 1998.

CHERVEL, André; Marie Madeleine, COMPÈRE. Les humanites dans l'histoire de l'enseignement français: histoire de l'éducation. Paris: INRP, 1997, p. 7-38.

COSTA, Wilma Peres. Viagens e peregrinações: a trajetória de intelectuais de dois mundos. In: BASTOS et al. (org.). 
Intelectuais: sociedade e política, Brasil-França. São Paulo: Cortez, 2003. p. $57-81$.

FREYRE, Gilberto. Um engenheiro francês no Brasil. Rio de Janeiro: José Olympio, 1940. Documentos brasileiros, v. 26.

GAMA, Lopes da (padre). Diagnóstico. Jornal do Commercio do Rio de Janeiro. Caderno Variedades, 25-26 mar. 1844, apud SHAPOCHNIK, Nelson. Das ficções do arquivo: ordem dos livros e práticas de leitura na Biblioteca Pública da Corte Imperial. In: ABREU, Márcia (org.). Leitura, história e história da leitura. Campinas, SP: Mercado das Letras: Associação de Leitura do Brasil; São Paulo: Fapesp, 1999, p. 302.

HEBRARD, Jean. A escolarização dos saberes elementares na época moderna. Teoria e Educação, n. 2, 1990, p. 65-109.

HEBRARD, Jean. Três figuras de jovens leitores: alfabetização do ponto de vista da história cultura. In: ABREU, Márcia. Leitura, história e história da leitura. Campinas, SP: Mercado das Letras; Associação de Leitura do Brasil; São Paulo: Fapesp, 1999. p. 33-77.

LAGES \& SILVA, Rita Cristina Lima; $\mathbf{O}$ ensino de francês em Minas Gerais entre 1831 e 1855. 2007. Dissertação (Mestrado) - Faculdade de Educação, Universidade Federal de Minas Gerais, Belo Horizonte.

LOPES, Eliane Marta Teixeira. Uma contribuição da história para uma história da educação. Em Aberto, Brasília : INEP, Vol. 9, no. 47, julho/setembro 1990, p. 29-35.

MORAIS, Christianni Cardoso. Para o aumento da instrução da mocidade da nossa pátria: estratégias de difusão do letramento na Vila de São João Del Rei (1824-1831). 2002. Dissertação(Mestrado em Educação) - Faculdade de Educação da Universidade Federal de Minas Gerais, Belo Horizonte, 2002. MOREL, Marco. As transformações dos espaços públicos: imprensa, atores políticos e sociabilidades na cidade imperial 
(1820-1840). São Paulo: Hucitec, 2005.

MUNIZ, Diva do Couto Gontijo.Um toque de gênero: história e educação em Minas Gerais(1835 - 1892). Brasília: Ed. UNB/ FINATEC, 2003.

PERRARD, M. J.-Ferréol. Logique classique d'après les principes de philosophie de M. Laromiguière. Séconde édition, Paris: Brunot-Labbe; Libraire de l'Université, 1834. Tome premier

PETITAT, André. Produção da escola / produção da sociedade: análise sócio-histórica de alguns momentos decisivos da evolução escolar no ocidente. Porto Alegre: Artes medicas, 1994.

RODRIGUES, José Carlos. Ideias filosóficas e políticas em Minas Gerais no século XIX. Belo Horizonte: Itatiaia; São Paulo: Ed. da Universidade de São Paulo, 1986.

SCHAPOCHNIK, Nelson. Das ficções do Arquivo: ordem dos livros e práticas de leitura na Biblioteca Pública da Corte Imperial. In: ABREU, Márcia. Leitura, história e história da leitura. Campinas, SP: Mercado das Letras: Associação de Leitura do Brasil; São Paulo: Fapesp, 1999. p. 273-311.

VILLALTA, Luiz Carlos. O que se fala e o que se lê: língua, instrução e leitura. In: SOUZA, Laura de Mello e (org.). História da vida privada no Brasil: cotidiano e vida privada na América portuguesa. São Paulo: Cia. das Letras, 1997.

VILLALTA, Luiz Carlos. Os leitores e os usos dos livros na América Portuguesa. In: ABREU, Márcia. Leitura, História e história da leitura. Campinas, SP: Mercado das Letras: Associação de Leitura do Brasil; São Paulo: Fapesp, 1999. p. $183-212$.

FONTES IMPRESSAS E MANUSCRITAS 
FUNDAÇÃO BIBLIOTECA NACIONAL. Catálogo de periódicos brasileiros microfilmados. Rio de Janeiro: Biblioteca Nacional, 1994.

MINAS GERAIS. Arquivo Público Mineiro. Diversos: provas e pareceres (Atas) - 1837... Instrução Pública. SP IP 3/3, cxs. 11 e 22 .

MINAS GERAIS. Arquivo Público Mineiro. Correspondências recebidas (1824-1863). Presidência da Província. SP PP 1/42, cxs 1 a 14.

MINAS GERAIS. Arquivo Público Mineiro. Documentação interna: mapas, aulas, posses, matrículas, etc. - 1827-1839. Instrução Pública. SP IP 3/2, cx 1.MINAS GERAIS. Arquivo Público Mineiro. Presidentes da Província/Fallas-1835-1842. Divisão de Obras Raras, OR PERI 0012, séc. XIX.

MINAS GERAIS. Relatórios dirigidos à Assembleia Legislativa Provincial de Minas Gerais pelos Presidentes da Província-1837-1889. Disponível em: http://ddsnext.crl.edu/ titles $/ 171 \#$ ? $\mathrm{c}=4 \& \mathrm{~m}=0 \& \mathrm{~s}=0 \& \mathrm{cv}=0 \& \mathrm{r}=0 \& \mathrm{xywh}=-1389 \% 2 \mathrm{C}$ 150\%2C4249\%2C2997. Acesso em: 01 de fev. 2020.

UNIVERSAL (O). Ouro Preto (1825-1842). Divisão de microfilmes/Biblioteca da FAFICH/UFMG. 